\title{
Team-based versus traditional primary care models and short-term outcomes after hospital discharge
}

\author{
Bruno D. Riverin PhD, Patricia Li MD MSc, Ashley I. Naimi PhD, Erin Strumpf PhD
}

Cite as: CMAJ 2017 April 24;189:E585-93. doi: 10.1503/cmaj.160427

\begin{abstract}
BACKGROUND: Strategies to reduce hospital readmission have been studied mainly at the local level. We assessed associations between population-wide policies supporting team-based primary care delivery models and short-term outcomes after hospital discharge.
\end{abstract}

METHODS: We extracted claims data on hospital admissions for any cause from 2002 to 2009 in the province of Quebec. We included older or chronically ill patients enrolled in team-based or traditional primary care practices. Outcomes were rates of readmission, emergency department visits and mortality in the 90 days following hospital discharge. We used inverse probability weighting to balance exposure groups on covariates and used marginal structural survival models to estimate rate differences and hazard ratios.

RESULTS: We included 620656 index admissions involving 312377 patients. Readmission rates at any point in the 90-day post-discharge period were similar between primary care models. Patients enrolled in team-based primary care practices had lower 30 -day rates of emergency department visits not associated with readmission (adjusted difference 7.5 per 1000 discharges, 95\% confidence interval $[\mathrm{Cl}] 4.2$ to 10.8 ) and lower 30-day mortality (adjusted difference 3.8 deaths per 1000 discharges,
$95 \% \mathrm{Cl} 1.7$ to 5.9$)$. The 30 -day difference for mortality differed according to morbidity level (moderate morbidity: 1.0 fewer deaths per 1000 discharges in team-based practices, $95 \% \mathrm{Cl} 0.3$ more to 2.3 fewer deaths; very high morbidity: 4.2 fewer deaths per 1000 discharges, $95 \% \mathrm{Cl} 3.0$ to $5.3 ; p<0.001$ ).

INTERPRETATION: Our study showed that enrolment in the newer team-based primary care practices was associated with lower rates of postdischarge emergency department visits and death. We did not observe differences in readmission rates, which suggests that more targeted or intensive efforts may be needed to affect this outcome.
H

ospital readmissions are costly, representing $\$ 1.8$ billion in annual health care spending in Canada (excluding fees for physician services). ${ }^{1}$ In the weeks following discharge, older or chronically ill patients are at increased risk of adverse events (e.g., complications or errors related to new medications), and many will return to the hospital. ${ }^{2-5}$ As many as 1 in 5 Medicare patients ( $\geq 65 \mathrm{yr}$ ) admitted to hospital for any cause in the United States are readmitted within 30 days after discharge, and about 1 in 4 patients return to the emergency department within that time..$^{6-8}$ Older age, increased comorbidity and complexity of medical condition are associated with using a disproportionate amount of health care resources across various settings ${ }^{9-12}$ and an increased risk of 30-day readmission. ${ }^{1,13-15}$

Hospital readmission has been the focus of much policy attention in the US and elsewhere as a potential intervention point and as a quality measure of hospital care. High rates of 30-day readmission may also indicate poor integration of the health care delivery sys- tem, one in which care is poorly coordinated across settings. ${ }^{16,17}$ Similarly, post-discharge emergency department visits, which account for about $40 \%$ of all acute post-discharge care encounters ${ }^{8}$ and contribute a meaningful share of hospital spending, ${ }^{1,18}$ have also been proposed as a novel marker of inadequate care coordination. ${ }^{7,8,18} \mathrm{~A}$ portion of all-cause hospital readmissions and post-discharge emergency department visits are deemed preventable., ${ }^{4,5,19,20}$ High population rates of such events represent opportunities to improve care and use health care resources more efficiently.

Interventions to reduce 30 -day readmissions and postdischarge emergency department visits have targeted organizational factors that play a role in care coordination, both in hospital ${ }^{21-24}$ and in outpatient settings. ${ }^{25}$ Most interventions studied have been resource intensive and implemented in local settings. ${ }^{26}$ Investigations of the capacity of innovations in primary care delivery implemented on a large scale to affect postdischarge outcomes are lacking. 
Primary care reform initiatives across Canada targeted many of the characteristics of the US Patient-Centered Medical Home model, including improved access, continuity and coordination of care. ${ }^{27-31}$ In Canada, the province of Quebec implemented Family Medicine Groups as a new practice model of multidisciplinary team-based primary care. Family Medicine Groups are designed to unite 6 to 12 family physicians and 1 or 2 nurses to provide primary care for a group of enrolled patients, with a broad range of services (e.g., case management, extended hours and emergency on-call services). ${ }^{32}$ By the end of 2005, about 100 Family Medicine Groups (230 sites) were operational in the province, although traditional primary care models (group or solo practices) remained the dominant type of primary health care organizations at the time. ${ }^{33}$

Our study objective was to assess whether rates of readmission, emergency department visits and mortality in the 90 days after hospital discharge differed between older or chronically ill patients enrolled in multidisciplinary team-based primary care practices and those enrolled in traditional practices. We performed subgroup analyses by patient morbidity level.

\section{Methods}

\section{Data source}

The Régie de l'assurance maladie du Québec (RAMQ) pays for health services provided by hospitals and physicians for all people registered with the province's universal health insurance program. We linked data from RAMQ databases using a unique lifetime identifier encrypted from the personal health insurance number. Data were obtained from the registered person files, which contain patient demographics; the physician claims files, which contain physician services performed in hospital, office or clinic; hospital files, which include information about each hospital admission; and physician information files, which contain information on the enrolling primary care physician, including practice type and characteristics, number of patients and services provided, and income source. RAMQ databases also contain information on the specialty of the billing physician.

\section{Study design}

The study is based on a large cohort of patients that has been described previously. ${ }^{34,35}$ The cohort was created through linkage of data from administrative health databases between November 2002 and January 2009 in Quebec, Canada. We extracted data on hospital admissions, emergency department visits and deaths that occurred during the study period and within 90 days after each hospital discharge. We used the index admission as the unit of analysis, which we defined as any hospital admission not preceded by a hospital discharge within 30 days. We included all index admissions for patients with multiple admissions.

We assigned exposure depending on whether a patient was enrolled with a primary care provider practising in a multidisciplinary team-based primary care practice (i.e., Family Medicine Group) or in a traditional primary care practice on the date of the index admission. Data for patients with multiple index admissions were included in different exposure groups if their type of enrolment changed.
We excluded index admissions to long-term care facilities and those that resulted in a discharge or a transfer to another facility. We also excluded index admissions for mental health ${ }^{1}$ and for pregnancy/childbirth using principal diagnostic codes (International Classification of Diseases, 9th and 10th revisions), sameday readmissions, admissions with in-hospital death, pediatric admissions, admissions with a hospital stay of 30 days or more and admissions to hospitals in northern Quebec. These admissions were excluded because they represent patient subgroups that likely differ with regards to the patterns of use and need of health care services.

\section{Study population}

Patients were selected into the original cohort study if a primary care physician enrolled them as a "vulnerable patient" between November 2002 and January 2005. Since 2002, primary care physicians enrol "vulnerable patients" into their practice by billing a fee code if a patient is 70 years of age or older or has one or more specified chronic health conditions, including psychosis, chronic obstructive pulmonary disease, moderate to severe asthma, pneumonia, cardiovascular disease, cancer associated with past, present or future chemotherapy or radiotherapy treatments, cancer in a terminal phase, diabetes, alcohol or drug withdrawal, drug addiction treated with methadone, HIV/ AIDS or a degenerative disease of the nervous system. ${ }^{36}$ The fee code is available to primary care providers in both new and traditional primary care practices.

\section{Outcome measures}

We considered the incidence of hospital readmission within 90 days after discharge as our primary outcome. For secondary outcomes, we examined the incidence of an emergency department visit and death up to 90 days after discharge. We further distinguished emergency department visits not associated with readmission, which included all visits for which there was no admission on the same day or following day.

\section{Covariates}

All covariates were measured at the time of the index admission. We included patient age, sex and major diagnostic categories, and time since enrolment by a primary care physician. We used a material deprivation index based on the 2006 census dissemination areas as a measure of neighbourhood socioeconomic status, and a categorical variable developed by the Quebec National Institute of Public Health to represent the patient's residential geographic location as a function of the proximity to an urban centre and to a tertiary or secondary referral hospital. ${ }^{37-39}$ We controlled for the number of previous admissions, the time since previous use of inpatient care, the patient morbidity level and relative intensity of hospital resource use. We assigned a patient morbidity level from 1 of 3 Resource Utilization Bands (moderate, high or very high) calculated using the Johns Hopkins Adjusted Clinical Groups Case-Mix System and based on diagnostic codes for both inpatient and outpatient utilization in the calendar year before the index admission. Resource Intensity Weights reflect the relative use of hospital resources, adjusted for age, comorbidities 
and complexity level..$^{40}$ In some specifications, we also included physician characteristics (age, sex, years in practice, total number of patients and income source [e.g., short-term care establishment, salary, emergency services]) and indicator variables for each hospital as covariates (Appendix 1, available at www.cmaj. ca/lookup/suppl/doi:10.1503/160427/-/DC1).

\section{Statistical analysis}

We first derived a propensity score from a logistic regression of Family Medicine Group enrolment at index admission on predictors. Covariates and model specifications are listed in Appendix 1. We derived stabilized inverse probability weights from propensity scores to balance covariates across exposure groups. We constructed separate sets of weights to investigate effect heterogeneity by morbidity level. Finally, we built flexible parametric survival mixture models weighted by inverse probability weights that allowed us to estimate both the subdistribution cumulative incidence functions and time-dependent cause-specific hazard ratios (HRs). ${ }^{41}$ The use of such models was necessary to account for competing risks (death and readmission) and for complex timedependent associations in the post-discharge period. ${ }^{42}$ We used cluster bootstrapping to obtain 95\% confidence intervals (Cls), and indicator variables or single imputation for missing data on covariates. We used Stata/MP 14 for all analyses.

\section{Ethics approval}

The Commission d'accès à l'information du Québec gave ethics approval.

\section{Results}

The cohort included 351113 older or chronically ill patients admitted to hospital in Quebec for any cause between November 2002 and January 2009, which represented 749537 hospital admissions. Of those admissions, we excluded 128881 (17.2\%) from 106176 patients (Figure 1). We included a total of 620656 index admissions for any cause (312377 patients). The stabilized inverse probability weights chosen had a mean close to 1 , small standard errors and a reasonable range (Appendix 2, available at www.cmaj.ca/lookup/ suppl/doi:10.1503/160427/-/DC1). ${ }^{43,44}$ Patient characteristics at index admission and standardized differences between exposure groups before and after weighting are shown in Table 1. After weighting, there were no standardized differences on measured covariates greater than $10 \%$ between team-based and traditional practices (Table 1).

We observed no meaningful or statistically significant differences in the cumulative incidence of hospital readmissions between team-based and traditional practices after adjusting for covariates (Table 2). Patients enrolled in team-based practices had a lower adjusted cumulative incidence of emergency department visits, of emergency department visits not associated with readmission and of death at 30 days after discharge and beyond (Table 2).

Table 3 shows cause-specific adjusted HRs estimated from marginal structural survival models for the association between enrolment in a team-based primary care practice at index ad- mission and readmission or emergency department visits. Relative to patients enrolled in traditional primary care practices, those in team-based practices had similar 30-day rates of readmission, $3 \%$ lower rates of emergency department visits and 5\% lower rates of emergency department visits not associated with readmission. The HRs typically moved slightly toward the null value between the 30th and the 90th day after discharge, except for readmission rates, which were $4 \%$ higher among patients enrolled in team-based practices by the end of the follow-up period (Table 3).

We found no statistically significant interaction between Family Medicine Group enrolment and morbidity level on the multiplicative scale. In Figure 2, we present the adjusted 30-day differences in cumulative incidence of postdischarge outcomes between team-based and traditional primary care practices by subgroup of patient morbidity level (i.e., additive scale). The 30-day difference for emergency department visits not associated with readmission differed according to morbidity level (moderate morbidity: 3.5 fewer visits per 1000 discharges in team-based practices, $95 \% \mathrm{Cl}$ 1.4 more to 8.4 fewer visits; very high morbidity: 10.3 fewer visits per 1000 discharges, $95 \% \mathrm{Cl} 5.4$ to 15.2 ), but it was not statistically significant $(p=0.3)$. The 30 -day difference for mortality differed significantly according to morbidity level (moderate morbidity: 1.0 fewer deaths per 1000 discharges in team-based practices, $95 \% \mathrm{Cl} 0.3$ more to 2.3 fewer deaths; very high morbidity: 4.2 fewer deaths per 1000 discharges, $95 \% \mathrm{Cl} 3.0$ to $5.3 ; p<0.001$ ).

\section{Interpretation}

In our study, about 1 in 4 older or chronically ill patients admitted to hospital for any cause returned to the hospital within 30 days after discharge (including readmission and emergency department

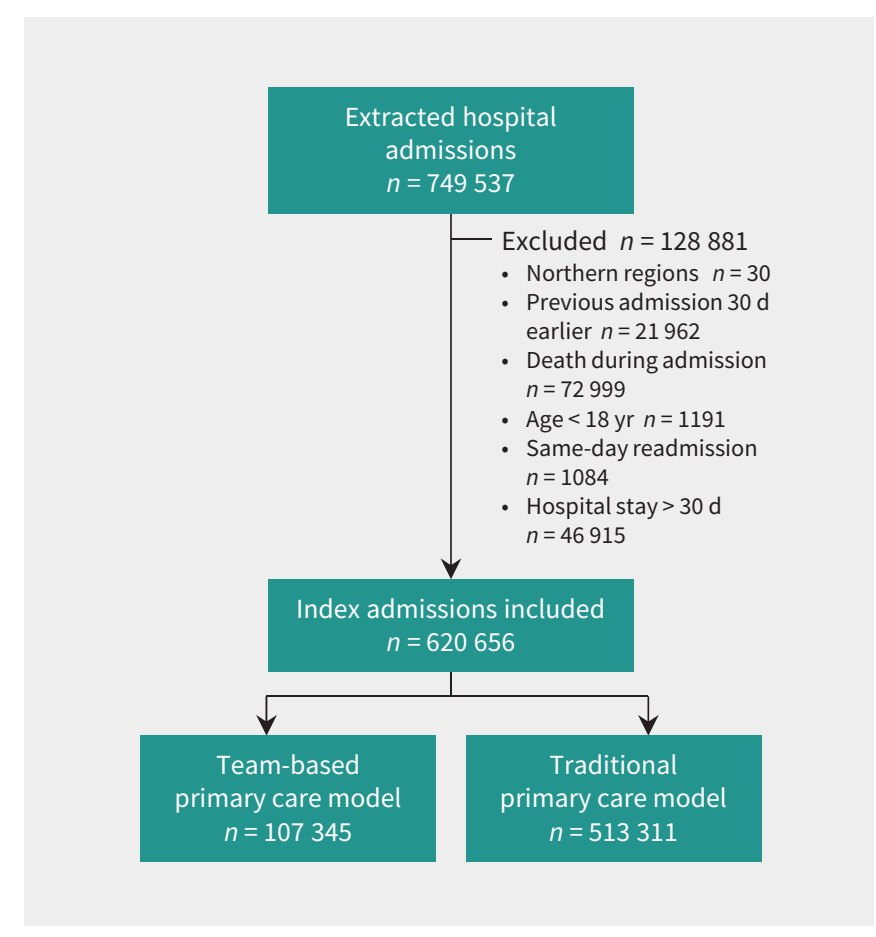

Figure 1: Selection of hospital admissions for the study. 
Table 1 (part 1 of 2): Characteristics at index admission of older or chronically ill patients admitted to hospital for any cause, by primary care model, $2002-2009^{*}$

\section{Characteristic}

\section{Patient characteristics}

Female sex, no. (\%)

Age, yr, mean

Morbidity level, no. (\%)

Moderate

High

Very high

Admission cost, Can\$, $†$ mean

Length of hospital stay, $d$, mean

Time since last admission, d, mean

Major diagnostic group, no. (\%)

Infectious and parasitic diseases

Tumours

Endocrine, nutritional and metabolic diseases

Diseases of the blood and blood-forming organs

Diseases of the nervous system

Diseases of the circulatory system

Diseases of the respiratory system

Diseases of the digestive system

Diseases of the respiratory system

Diseases of the skin and subcutaneous tissue

Diseases of musculoskeletal system and connective tissue

Diseases of the genitourinary tract

Symptoms, signs and ill-defined conditions

Congenital anomalies or birth defect

Extraneous causes of morbidity/mortality, abnormal findings

Injuries and poisoning

Factors influencing health and contact with health services

Time since enrolment with primary care physician, yr, mean

Year of index admission, no. (\%)

\section{2/03ł}

2004

2005

2006

2007

2008/09

Material deprivation quintile, $\%$

1 (low)
2
3
4

Primary care model

$\begin{array}{ll}\text { Team-based } & \text { Traditional } \\ n=107345 & n=513311\end{array}$

56568 (52.7)

73.3

270672 (52.7)

73.3

$19136(17.8)$
$30677(28.6)$
$57532(53.6)$
5656
7.2
400

$2184(2.0)$

$10618(9.9)$

2015 (1.9)

$1971(1.8)$

2968 (2.8)

14392 (13.4)

$7542(7.0)$

$20799(19.4)$

$11226(10.5)$

$1449(1.3)$

$7105(6.6)$

$3312(3.1)$

4240 (3.9)

$3797(3.5)$

$7014(6.5)$

$5107(4.8)$

$1606(1.5)$

$$
2.5
$$

$9524(8.9)$

$19088(17.8)$

$21317(19.9)$

19210 (17.9)

18556 (17.3)

$19650(18.3)$

11166 (10.4)

$17142(16.0)$

$22266(20.7)$

25249 (23.5)

86812 (16.9)

$143285(27.9)$

283214 (55.2)

5656

7.2

409

$10764(2.1)$

54298 (10.6)

2.5

81184 (15.8)

$33287(6.5)$

71791 (14.0)

83240 (16.2)

99303 (19.3)

107648 (21.0)
Absolute standardized

difference, $\%$

$\begin{array}{cc}\begin{array}{c}\text { Before } \\ \text { weighting }\end{array} & \begin{array}{c}\text { After } \\ \text { weighting }\end{array}\end{array}$

2.4

0.0

1.5

0.1

1.3

3.8

3.2

0.2

0.2

0.1

0.1

4.7

1.9

0.4

0.0

2.3

0.7

0.1

0.6

0.1

1.4

0.3

0.4

0.2

0.3

0.0

0.5

0.7

0.4

0.4

0.6

0.4

0.3

16.2

21.2

1.1

5.9

2.2

1.3

0.8

2.8

0.4

31.0

11.0

0.1

0.2

0.7

1.1
3.5

6.1 
Table 1 (part 2 of 2): Characteristics at index admission of older or chronically ill patients admitted to hospital for any cause, by primary care model, 2002-2009*

\begin{tabular}{|c|c|c|c|c|}
\hline \multirow[b]{2}{*}{ Characteristic } & \multicolumn{2}{|c|}{ Primary care model } & \multicolumn{2}{|c|}{$\begin{array}{l}\text { Absolute standardized } \\
\text { difference, } \%\end{array}$} \\
\hline & $\begin{array}{l}\text { Team-based } \\
n=107345\end{array}$ & $\begin{array}{l}\text { Traditional } \\
n=513311\end{array}$ & $\begin{array}{c}\text { Before } \\
\text { weighting }\end{array}$ & $\begin{array}{c}\text { After } \\
\text { weighting }\end{array}$ \\
\hline 5 (high) & $23418(21.8)$ & $116428(22.7)$ & 2.1 & 2.1 \\
\hline Missing & $8104(7.5)$ & $34901(6.8)$ & 2.9 & 1.7 \\
\hline \multicolumn{5}{|l|}{ Geographic region, no. (\%) } \\
\hline Urban/university§ & $24461(22.8)$ & $184971(36.0)$ & 29.4 & 1.8 \\
\hline Suburban & $45359(42.3)$ & $197775(38.5)$ & 7.6 & 0.5 \\
\hline Intermediate & $30301(28.2)$ & $100593(19.6)$ & 20.3 & 0.4 \\
\hline Rural & $7014(6.5)$ & $28277(5.5)$ & 4.3 & 1.8 \\
\hline Missing & $210(0.2)$ & $1695(0.3)$ & 2.6 & 0.3 \\
\hline \multicolumn{5}{|l|}{ Enrolling primary care physician characteristics } \\
\hline Female sex, no. (\%) & $25339(23.6)$ & $121211(23.6)$ & 7.1 & 2.0 \\
\hline Time since graduation, yr, mean & 23.8 & 24.7 & 11.9 & 5.1 \\
\hline No. of patients per year, mean & 2104 & 1857 & 23.4 & 0.6 \\
\hline $\begin{array}{l}\% \text { of physicians with proportion of income from acute care } \\
\text { establishment } \geq 80 \%\end{array}$ & 2.0 & 0.0 & 15.7 & 1.1 \\
\hline
\end{tabular}

visits). Patients enrolled in team-based primary care practices had a 5\% lower 30-day risk of emergency department visit not associated with readmission, and significantly fewer patients died in the early period after hospital discharge compared with patients enrolled in traditional primary care practices. The strength of these associations diluted beyond 30 days after discharge. We did not find that team-based primary care delivery models were associated with lower rates of readmission within 30 days. In fact, rates of readmission were on average higher by $4 \%$ among patients enrolled in team-based practices over the complete 90 days of follow-up after discharge. Lower 30-day rates of death associated with enrolment in team-based primary care were predominantly observed among patients within the highest level of morbidity.

Several factors or mechanisms may influence rates of readmission, emergency department visits and death, including patient(e.g., severity of illness), physician- and community-level factors that are not captured in administrative health databases. Unmeasured differences in case-mix across primary care delivery models compared in this study may have biased our analytical results. Family Medicine Group practices may enrol patients with less functional limitations or with lower severity, which in turn would make them appear to perform better in terms of mortality and other postdischarge outcome measures. To minimize the risk of residual confounding, we effectively balanced measured covariates that we believe to be reasonable proxies for patient health status and severity at index admission, and we modelled covariates, timedependent effects and interactions flexibly (e.g., restricted cubic splines). Further, physician participation and patient enrolment in primary care models depend largely on physician preferences and characteristics (e.g., physicians who joined Family Medicine Groups have less years of practice), which may in turn affect the way patients are managed in an outpatient setting. ${ }^{34}$ The use of inverse probability weights based on measured physician and patient characteristics at index admission may have accounted for this selection bias to some degree, but not completely.

In the absence of unmeasured confounding, that team-based primary care practices were associated with lower mortality but not lower readmission rates suggests that Family Medicine Group practices keep their sickest patients alive longer, which in turn increases their likelihood of being readmitted. ${ }^{45}$ This hypothesis is consistent with the lower mortality that occurred predominantly among patients in the higher morbidity subgroups, and with the higher rates of readmission among Family Medicine Group patients that occurred later in the follow-up period rather than earlier. However, in this study, the subdistribution cumulative incidence functions and the cause-specific HRs were qualitatively similar, which suggests that competing events (e.g., death) played a minor role in driving associations with readmission and other postdischarge care encounters. ${ }^{46,47}$

That lower rates of postdischarge emergency department visits not associated with readmission and mortality associated with team-based primary care practices occurred primarily among patients in the highest morbidity level suggests that nurses and physicians in Family Medicine Group practices 
achieve better results in the coordination of care for the highest users in the health care system. In a parallel study, we reported that rates of postdischarge follow-up by a primary care physician were higher among patients with very high morbidity enrolled in a Family Medicine Group, ${ }^{48}$ which is consistent with the above hypothesis. Nurses in primary care teams likely play a role in providing follow-up services in the postdischarge period, but this information is not captured in Quebec administrative health databases. Although early evaluations of Quebec primary care reforms highlighted important variations in how interdisciplinary collaboration was implemented in Family Medicine Groups, ${ }^{49}$ the roles and tasks of nurses in the design of the Family Medicine Group policy include systematic follow-up and case management for patients with complex medical needs. Future research

\section{Table 2: Unadjusted and adjusted* differences in cumulative incidence of postdischarge outcomes among older or chronically} ill patients admitted to hospital, by primary care model

\section{Primary care model; unadjusted rate per 1000 discharges}

\section{Postdischarge outcome}

Team-based

\section{Difference in rate $(95 \% \mathrm{Cl}+)$}

\section{Within $30 \mathrm{~d}$}

Readmission

Emergency department visit

Emergency department visit not associated with readmission

Death

\section{Within $90 \mathrm{~d}$}

Readmission

Emergency department visit

Emergency department visit

not associated with readmission

Death

\begin{tabular}{ll}
136.3 & 140.6 \\
201.3 & 210.0 \\
159.4 & 170.1 \\
\hline 13.1 & 16.8 \\
\hline 253.0 & 256.7 \\
321.4 & 331.4 \\
255.7 & 269.4 \\
& \\
\hline 22.6 & 27.0
\end{tabular}

Unadjusted

$-4.3(-6.6$ to -1.9$)$

$-8.8(-13.1$ to -5.7$)$

$-10.7(-14.0$ to -8.2$)$

$-3.7(-4.4$ to -2.9$)$

$-3.5(-7.5$ to 0.1$)$

$-10.0(-14.3$ to -7.1$)$

$-13.7(-17.3$ to -11.0$)$

$-4.4(-4.4$ to -3.4$)$

\section{Adjusted}

Note: $\mathrm{Cl}=$ confidence interval.

*All index admissions $(n=620656)$ were included in the analysis. Covariates and 2-way interactions adjusted for are listed in Appendix 1 (available at www.cmaj.ca/lookup/suppl/ doi:10.1503/160427/-/DC1).

tCluster bootstrapping was used to obtain $95 \%$ Cls.

Table 3: Unadjusted and adjusted* cause-specific hazard ratios (HRs) for the association between enrolment in team-based primary care practice at index admission and postdischarge outcomes

\begin{tabular}{|c|c|c|}
\hline Postdischarge outcome & $\begin{array}{l}\text { Unadjusted HR } \\
\left.\text { (95\% CI })^{\prime}\right)\end{array}$ & $\begin{array}{l}\text { Adjusted HR } \\
\text { (95\% CI } \dagger \text { ) }\end{array}$ \\
\hline \multicolumn{3}{|l|}{ Within $30 \mathrm{~d}$} \\
\hline Readmission & 0.98 (0.95 to 1.01$)$ & 1.01 (0.96 to 1.04$)$ \\
\hline Emergency department visit & 0.95 (0.93 to 0.97$)$ & 0.97 (0.93 to 1.00$)$ \\
\hline $\begin{array}{l}\text { Emergency department visit not } \\
\text { associated with readmission }\end{array}$ & 0.92 (0.90 to 0.95$)$ & 0.95 (0.91 to 0.98$)$ \\
\hline Death & 0.88 (0.82 to 0.95$)$ & 0.95 (0.92 to 0.98$)$ \\
\hline \multicolumn{3}{|l|}{ Within $90 \mathrm{~d}$} \\
\hline Readmission & 1.01 (0.98 to 1.04$)$ & 1.04 (1.00 to 1.07$)$ \\
\hline Emergency department visit & 1.00 (0.97 to 1.03$)$ & 0.99 (0.95 to 1.02$)$ \\
\hline $\begin{array}{l}\text { Emergency department visit not } \\
\text { associated with readmission }\end{array}$ & 0.97 (0.94 to 1.00$)$ & 0.97 (0.92 to 1.00$)$ \\
\hline Death & 0.93 (0.84 to 1.04$)$ & $0.97(0.93$ to 1.00$)$ \\
\hline
\end{tabular}


should investigate the role played by primary care nurses for recently discharged patients. In addition, because postdischarge follow-up by nurses was not specifically addressed in the Family Medicine Group policy, this represents a potential intervention point that could further affect patient outcomes and cost of care.

Our study is unique in examining patterns of readmissions and other post-discharge events in the context of system-level efforts to transform primary care delivery. Results from other studies that examined practice-level (or "bottom-up") innovations implemented locally and with greater intensity may provide insight into future policy targets to scale up Canadian reforms. In the US, many of the primary care practices studied thus far that undertook transformation for enhanced care coordination within the Patient-Centered Medical Home framework were found to have significantly lower readmission rates. ${ }^{50-54}$ These often included case management, multidisciplinary teams and postdischarge follow-up. Of note, the Patient-Centered Medical Home model strongly emphasize care coordination across all elements of the health care system (e.g., hospitals, home health care, community resources and supports). The same level of emphasis on care coordination was not observed when Quebec's Family Medicine Group policy was implemented. Strategies for care coordination examined in recent systematic reviews and meta-analyses of randomized controlled trials also found that involving more individuals in postdischarge care delivery (e.g., multidisciplinary teams and care managers) as well as support- ing patient capacity for self-care led to significant reductions in hospital admissions or readmissions. ${ }^{25,55} \mathrm{~A}$ compilation of studies also found that postdischarge follow-up was associated with reductions in readmission rates, ${ }^{56-61}$ including one study conducted by our research team that highlighted particularly important reductions if follow-up was provided in a timely manner in a primary care setting (unpublished data). Consistent with our results, the evidence on team-based primary care models in Canada have pointed to small improvements in health utilization measures (not specifically in the postdischarge period), mainly lower rates of hospital admission and emergency department visits among older or chronically ill patients, and some improvements in processes of care..$^{35,62-65}$

\section{Limitations and strengths}

As discussed earlier, the causal interpretation of our results is tempered by potential sources of bias, most notably by unmeasured confounding due to severity of illness and functional limitations of patients and by selection bias due to physician preferences and practice behaviours.

Our study has several methodologic strengths. We used data for more than 600000 admissions that occurred from 2002 to 2009. The large database of patients used in this study likely reflects the population of older or chronically ill patients in Quebec who visited a primary care physician, which greatly improves the generalizability of our findings. We also used methods to address various biases,

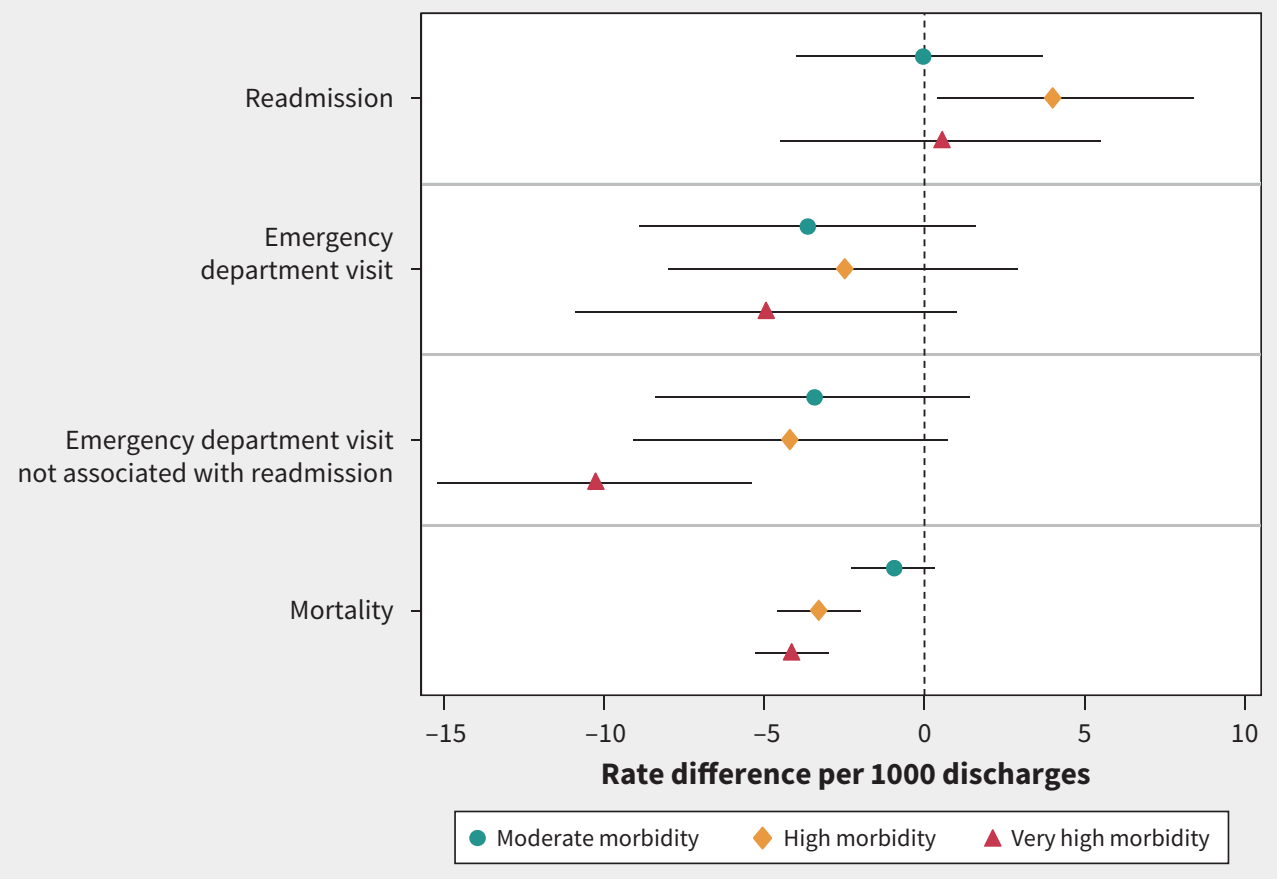

Figure 2: Adjusted differences in 30-day cumulative incidence of postdischarge outcomes between team-based and traditional primary care practices, by morbidity level. Error bars represent clustered $95 \%$ confidence intervals. Values less than zero indicate a decreased likelihood of the outcome. Exact numbers associated with this figure are provided in Appendix 3. Covariates and 2-way interactions adjusted for are listed in Appendix 1. (Appendices are available at www.cmaj.ca/lookup/suppl/doi:10.1503/160427/-/DC1.) 
including inverse probability weighting to address selection and collider-stratification bias, and flexible modelling of covariates and time-dependent effects to address model misspecification.

\section{Conclusion}

Our study showed that the newer team-based primary care delivery model in Quebec was associated with some better postdischarge outcomes among older or chronically ill patients, notably lower rates of emergency department visits and death. We did not observe differences in the 30-day rate of readmission between team-based and traditional practices, although the rate of readmission beyond 30 days seemed to be slightly higher among patients enrolled in team-based practices, which may or may not have been due to patients surviving longer in this group. The lack of an association between enrolment in a team-based primary care practice and readmission, and the lack of differences in any of the outcomes among patients in the lower spectrum of medical complexity, suggests that more targeted or intensive efforts may be needed to improve postdischarge outcomes among older or chronically ill patients.

\section{References}

1. All-cause readmission to acute care and return to the emergency department. Ottawa: Canadian Institute for Health Information; 2012.

2. Krumholz HM. Post-hospital syndrome - an acquired, transient condition of generalized risk. N Engl J Med 2013;368:100-2.

3. Dharmarajan K, Hsieh AF, Kulkarni VT, et al. Trajectories of risk after hospitalization for heart failure, acute myocardial infarction, or pneumonia: retrospective cohort study. BMJ 2015;350:h411.

4. Forster AJ, Murff HJ, Peterson JF, et al. The incidence and severity of adverse events affecting patients after discharge from the hospital. Ann Intern Med 2003;138:161-7.

5. Calder L, Pozgay A, Riff S, et al. Adverse events in patients with return emergency department visits. BMJ Qual Saf 2015;24:142-8.

6. Jencks SF, Williams MV, Coleman EA. Rehospitalizations among patients in the Medicare fee-for-service program. N Engl J Med 2009;360:1418-28.

7. Rising KL, White LF, Fernandez WG, et al. Emergency department visits after hospital discharge: a missing part of the equation. Ann Emerg Med 2013; 62:145-50.

8. Vashi AA, Fox JP, Carr BG, et al. Use of hospital-based acute care among patients recently discharged from the hospital. JAMA 2013;309:364-71.

9. Aminzadeh F, Dalziel WB. Older adults in the emergency department: a systematic review of patterns of use, adverse outcomes, and effectiveness of interventions. Ann Emerg Med 2002;39:238-47.

10. Wofford JL, Schwartz E, Timerding BL, et al. Emergency department utilization by the elderly: analysis of the National Hospital Ambulatory Medical Care Survey. Acad Emerg Med 1996;3:694-9.

11. Schoen C, Osborn R, Squires D, et al. New 2011 survey of patients with complex care needs in eleven countries finds that care is often poorly coordinated. Health Aff (Millwood) 2011;30:2437-48.

12. Wodchis WP, Austin PC, Henry DA. A 3-year study of high-cost users of health care. CMAJ 2016;188:182-8.

13. Mudge AM, Kasper K, Clair A, et al. Recurrent readmissions in medical patients: a prospective study. J Hosp Med 2011;6:61-7.

14. Bjorvatn A. Hospital readmission among elderly patients. Eur J Health Econ 2013;14:809-20.

15. Shadmi E, Flaks-Manov N, Hoshen M, et al. Predicting 30-day readmissions with preadmission electronic health record data. Med Care 2015;53:283-9.

16. Monette M. Hospital readmission rates under the microscope. CMAJ 2012;184: E651-2.

17. Colla $\mathrm{CH}$, Wennberg DE, Meara E, et al. Spending differences associated with the Medicare Physician Group Practice Demonstration. JAMA 2012;308:1015-23.

18. Kocher KE, Nallamothu BK, Birkmeyer JD, et al. Emergency department visits after surgery are common for Medicare patients, suggesting opportunities to improve care. Health Aff (Millwood) 2013;32:1600-7.

19. van Walraven $C$, Bennett $C$, Jennings $A$, et al. Proportion of hospital readmissions deemed avoidable: a systematic review. CMAJ 2011;183:E391-402.
20. Forster AJ, Clark HD, Menard A, et al. Adverse events among medical patients after discharge from hospital. CMAJ 2004;170:345-9.

21. Allen J, Hutchinson AM, Brown R, et al. Quality care outcomes following transitional care interventions for older people from hospital to home: a systematic review. BMC Health Serv Res 2014;14:346.

22. Feltner $\mathrm{C}$, Jones CD, Cene CW, et al. Transitional care interventions to prevent readmissions for persons with heart failure: a systematic review and meta-analysis. Ann Intern Med 2014;160:774-84.

23. Rennke S, Nguyen OK, Shoeb MH, et al. Hospital-initiated transitional care interventions as a patient safety strategy: a systematic review. Ann Intern Med 2013; 158:433-40.

24. Verhaegh KJ, MacNeil-Vroomen JL, Eslami S, et al. Transitional care interventions prevent hospital readmissions for adults with chronic illnesses. Health Aff (Millwood) 2014;33:1531-9.

25. Tricco AC, Antony J, Ivers NM, et al. Effectiveness of quality improvement strategies for coordination of care to reduce use of health care services: a systematic review and meta-analysis. CMAJ 2014;186:E568-78.

26. Hansen LO, Young RS, Hinami K, et al. Interventions to reduce 30-day rehospitalization: a systematic review. Ann Intern Med 2011;155:520-8.

27. Levine D. The reform of health and social services in Quebec. Healthc Pap 2007; 8:46-54.

28. À propos des GMF : Pourquoi créer des groupes de médicine de famille (GMF) ? Quebec: Ministère de la Santé et des Services Sociaux; 2010.

29. Romanow RJ. Building on values: the future of health care in Canada. Saskatoon: Commission of the Future of Healthcare in Canada; 2002. Available: http://publications.gc.ca/collections/Collection/CP32-85-2002E.pdf (accessed 2010 Oct. 31).

30. Benderix Y, Sivberg B. Siblings' experiences of having a brother or sister with autism and mental retardation: a case study of 14 siblings from five families. J Pediatr Nurs 2007;22:410-8.

31. Strumpf E, Levesque JF, Coyle N, et al. Innovative and diverse strategies toward primary health care reform: lessons learned from the Canadian experience. J Am Board Fam Med 2012;25(Suppl 1):S27-33.

32. Rapport d'appréciation de la performance du système de santé et de services sociaux. Construire sur les bases d'une première ligne de soins renouvelée : recommandations, enjeux et implications. Québec (QC): Commissaire à la santé et au bien-être; 2009. Available: www.csbe.gouv.qc.ca/fileadmin/www/2009_PremiereLigne/ format2pages/csbe-Recommandations-t4-2p-042009.pdf (accessed 2017 Jan. 30).

33. Dubé F. Direction de l'organisation des services de première ligne intégrés, Quebec: Ministère de la Santé et des Services Sociaux; 2015.

34. Coyle N, Strumpf E, Fiset-Laniel J, et al. Characteristics of physicians and patients who join team-based primary care practices: evidence from Quebec's Family Medicine Groups. Health Policy 2014;116:264-72.

35. Héroux J, Moodie EEM, Strumpf E, et al. Marginal structural models for skewed outcomes: identifying causal relationships in health care utilization. Stat Med 2014;33:1205-21.

36. Groupe de médecine de famille (GMF) [33-1]. In: 4. Ententes particulières. Brochure 1 - Omnipraticiens. Montréal: Régie de l'assurance maladie du Québec; 2016.

37. Pampalon R. Indice de défavorisation matérielle et sociale: son application au secteur de la santé et du bien-être. Santé, Société et Solidarité 2003;1.

38. Pampalon R, Gamache P, Hamel D. Indice de défavorisation matérielle et sociale du Québec: suivi méthodologique de 1991 à 2006. Québec: Institut National de Santé Publique du Québec, 2010.

39. Gauthier J, Haggerty J, Lamarche P, et al. Entre adaptabilité et fragilité: les conditions d'accès aux services de santé des communautés rurales et éloignées. Institut National de Santé Publique du Québec; 2009.

40. Daneault S, Fournier J. Gravité clinique, niveau d'accès et NIRRU : document synthèse. Longueuil $(\mathrm{QC})$ : Agence de la santé et des services sociaux de la Montérégie; 2014. Available: http://extranet.santemonteregie.qc.ca/depot/document/3612/ Gravit\%C3\%A9_niveau_acces_NIRRU_APR-DRG_2014-04-04.pdf (accessed 2017 Jan. 30).

41. Royston P, Lambert PC. Flexible parametric survival analysis using Stata: beyond the Cox Model. College Station (TX): Stata Press; 2011.

42. Lambert PC. Extending the flexible parametric survival model for competing risks. Stata J 2013;13:344-55

43. Cole SR, Hernan MA. Constructing inverse probability weights for marginal structural models. Am J Epidemiol 2008;168:656-64.

44. Austin PC, Stuart EA. Moving towards best practice when using inverse probability of treatment weighting (IPTW) using the propensity score to estimate causal treatment effects in observational studies. Stat Med 2015;34:3661-79.

45. Joynt KE, Jha AK. Thirty-day readmissions-truth and consequences. N Engl J Med 2012;366:1366-9.

46. Austin PC, Lee DS, Fine JP. Introduction to the Analysis of Survival Data in the Presence of Competing Risks. Circulation 2016;133:601-9. 
47. Lau B, Cole SR, Gange SJ. Competing risk regression models for epidemiologic data. Am J Epidemiol 2009;170:244-56.

48. Riverin BD, Li P, Naimi Al, et al. Team-based innovations in primary care delivery in Quebec and timely physician follow-up after hospital discharge: a populationbased cohort study. CMAJ Open 2017;5:E28-35.

49. Evaluation de l'implantations et des effets des premiers groupes de médecine de famille au Québec. Québec: Ministère de la Santé et des Services Sociaux; 2008.

50. White B, Carney PA, Flynn J, et al. Reducing hospital readmissions through primary care practice transformation. J Fam Pract 2014;63:67-73.

51. Gilfillan RJ, Tomcavage J, Rosenthal MB, et al. Value and the medical home: effects of transformed primary care. Am J Manag Care 2010;16:607-14.

52. Maeng DD, Khan N, Tomcavage J, et al. Reduced acute inpatient care was largest savings component of Geisinger Health System's Patient-Centered Medical Home. Health Aff(Millwood) 2015;34:636-44.

53. Stranges PM, Marshall VD, Walker PC, et al. A multidisciplinary intervention for reducing readmissions among older adults in a Patient-Centered Medical Home. Am J Manag Care 2015;21:106-13.

54. Cavanaugh JJ, Jones CD, Embree G, et al. Implementation Science Workshop: primary care-based multidisciplinary readmission prevention program. J Gen Intern Med 2014;29:798-804.

55. Leppin AL, Gionfriddo MR, Kessler M, et al. Preventing 30-day hospital readmissions: a systematic review and meta-analysis of randomized trials. JAMA Intern Med 2014;174:1095-107.
56. Sharma G, Kuo YF, Freeman JL, et al. Outpatient follow-up visit and 30-day emergency department visit and readmission in patients hospitalized for chronic obstructive pulmonary disease. Arch Intern Med 2010;170:1664-70.

57. Misky GJ, Wald HL, Coleman EA. Post-hospitalization transitions: examining the effects of timing of primary care provider follow-up. J Hosp Med 2010;5:392-7.

58. Lin CY, Barnato AE, Degenholtz HB. Physician follow-up visits after acute care hospitalization for elderly Medicare beneficiaries discharged to noninstitutional settings. J Am Geriatr Soc 2011;59:1947-54

59. Jackson C, Shahsahebi M, Wedlake T, et al. Timeliness of outpatient follow-up: an evidence-based approach for planning after hospital discharge. Ann Fam Med 2015;13:115-22.

60. Hernandez AF, Greiner MA, Fonarow GC, et al. Relationship between early physician follow-up and 30-day readmission among Medicare beneficiaries hospitalized for heart failure. JAMA 2010;303:1716-22.

61. Brooke BS, Stone DH, Cronenwett JL, et al. Early primary care provider follow-up and readmission after high-risk surgery. JAMA Surg 2014;149:821-8.

62. Manns BJ, Tonelli M, Zhang J, et al. Enrolment in primary care networks: impact on outcomes and processes of care for patients with diabetes. CMAJ 2012;184:E144-52.

63. Campbell DJ, Ronksley PE, Hemmelgarn BR, et al. Association of enrolment in primary care networks with diabetes care and outcomes among First Nations and low-income Albertans. Open Med 2012;6:e155-65.

64. Kiran T, Kopp A, Moineddin R, et al. Longitudinal evaluation of physician payment reform and team-based care for chronic disease management and prevention. CMAJ 2015;187:E494-502.

\section{Competing interests: None declared.}

This article has been peer reviewed.

Affiliations: Department of Epidemiology, Biostatistics and Occupational Health (Riverin, Li, Strumpf), McGill University; Department of Pediatrics (Riverin, Li), Montreal Children's Hospital, McGill University Health Centre, Montréal, Que.; Department of Epidemiology (Naimi), University of Pittsburgh Graduate School of Public Health, Pittsburgh, Penn.; Direction de la santé publique du CIUSS du Centre-Sud-de-l'île-de-Montréal (Strumpf); Department of Economics (Strumpf), McGill University, Montréal, Que.
Contributors: All of the authors contributed to the study conception and design, and to the analysis and interpretation of the data. Bruno Riverin drafted the manuscript; Patricia Li, Ashley Naimi and Erin Strumpf revised it critically for important intellectual content. All of the authors approved the final version to be published and agreed to act as guarantors of the work.

Funding: Bruno Riverin is funded by the Fonds de recherche du Québec - Santé, Unité SUPPORT du Québec, and a Partnerships for Health System Improvement grant from the Canadian Institutes of Health Research. Patricia Li was funded by a Chercheur-boursier clinicien Junior 1 from the Fonds de Recherche du Québec - Santé and the Ministère de la Santé et des Services sociaux du Québec, and a New Investigator Salary Award from the Canadian Institutes of Health Research. Erin Strumpf was funded by a Chercheur-boursier Junior 1 from the Fonds de Recherche du Québec - Santé and the Ministère de la Santé et des Services sociaux du Québec. No other competing interests were declared.

Accepted: Jan. 3, 2017

Correspondence to: Bruno Riverin, bruno.riverin@mail.mcgill.ca 